\title{
Off-label medication use in rare pediatric diseases in the United States
}

\author{
Albert Fung $^{1}$, Xiaomeng Yue ${ }^{1,2, *}$, Patricia R. Wigle ${ }^{1}$, Jeff J. Guo ${ }^{1}$ \\ ${ }^{1}$ Division of Pharmacy Practice \& Administrative Sciences, James L. Winkle College of Pharmacy, University of Cincinnati Academic Health Center, \\ Cincinnati, Ohio, USA; \\ ${ }^{2}$ Joulé, Edison, New Jersey, USA.
}

SUMMARY Many pediatric patients with rare diseases use drugs off-label due to limited data in pediatric patients. Off-label treatment remains an important public health issue for neonates, infants, children, and adolescents, especially for pediatric patients with rare diseases. For patients with rare diseases, the majority of medications have no or limited information in labelling for pediatric use. Children present unique considerations in clinical trials due to ethical and clinical concerns, which have limited and even discouraged testing of drugs in the pediatric population. Numerous legislative measures have been enacted to address barriers in pediatric drug testing. This research reviewed off-label medication use in rare pediatric diseases, evaluated recent medication uses in pediatric clinical practice, discussed key regulations for rare pediatric diseases, and summarized recent drug approvals for rare pediatric diseases. This study demonstrates the ongoing medical need for newly approved medications to treat pediatric rare diseases and revealed the positive impact of regulations from the Orphan Drug Act of 1983 to the Research to Accelerate Cures and Equity (RACE) for Children Act on drug development and off-label medication practice in rare pediatric disease management. This article provides informative historical background and current considerations of off-label use of medications in neonates, infants, children, and adolescents with rare diseases.

Keywords rare diseases, off-label drug use, pediatrics, infants, children.

\section{Introduction}

While many drugs have been approved by the U.S. Food and Drug Administration (FDA) for use in adults, the lack of studies in children often leads to off-label usage of drugs in children. A drug will only have FDA approved labelling for use in children if the FDA has determined the drug's safety and effectiveness for a particular condition in children. There are delays in conducting clinical trials with children due to a lack of financial incentives for sponsors to conduct drug trials with children. Also, many diseases are less common in children than in adults, so it requires more time to recruit child participants. In addition, there are often concerns regarding ethics, harm, and consent, making it difficult to obtain institutional review board approval to conduct clinical trials with children. The risk of improper dosing or usage of drugs in children may cause harm. In addition, the resulting hospitalizations and administration of off-label treatments are major health care cost drivers and concerns.

There have already been several governmental legislations that have been set up to address off-label use in children. For instance, the Pediatric Research Equity Act (PREA) of 2003 requires pharmaceutical companies to study effects of new drugs on children if the drugs have the potential to be prescribed to children (1). Under the PREA policy, when sponsors submit a new drug application to the FDA for approval in adults, they also have to provide information on safety and efficacy of the drug in children. Studies under PREA are mandatory and those under the Best Pharmaceuticals for Children Act (BPCA) are voluntary. BPCA gives pharmaceutical companies six additional months of patent use for drugs already on the market if the companies conduct clinical trials for children (2). These regulations not only support the need for pediatric safety, efficacy, and dosing information, but also enhance transparency of the drug approval process.

Unfortunately, these laws have very limited application to orphan therapies for rare diseases. The majority of rare diseases start in childhood and more than half of patients with rare diseases are children. Increasing rates of off-label prescribing patterns in 
children were observed from 2006 to 2015, particularly for unapproved conditions (3). With this consideration in mind, the objective of this article is to review current considerations and historical background of off-label use of medication in pediatric patients with rare diseases.

\section{Off-label use for rare pediatric diseases}

There are over 7,000 known rare diseases, with many new ones being discovered (4). According to the Orphan Drug Act of 1983, each rare disease affects fewer than 200,000 people in the United States (5). Although the number of patients affected for each rare condition is small, approximately 25-30 million are affected by those rare diseases in the United States (4). Approximately $80 \%$ of rare diseases are genetic in origin, and approximately half of affected individuals are children $(6)$.

While significant advances in the development and approval of rare disease therapies have been made, most rare conditions still have no treatments. Only $5-7 \%$ of rare diseases have an FDA approved drug (7). For example in 2017, FDA approved cerliponase alfa (Brineura ${ }^{\mathrm{TM}}$ ) as the first treatment for neuronal ceroid lipofuscinosis type 2 (CLN2) disease (8). CLN2 disease, also known as late infantile neuronal ceroid lipofuscinosis (NCL), is a form of Batten's Disease which is a rare, autosomal recessive, pediatric neurodegenerative disease that results from pathogenic variants in the gene encoding lysosomal enzyme tripeptidyl peptidase 1 (TPP1) (9). Before cerliponase alfa, there were no approved pharmacological treatments for CLN2 other than drugs for symptom management.

There are many challenges in developing new drugs for rare diseases. Besides ethical issues related to enrolling children in clinical trials, rare pediatric diseases are frequently underdiagnosed because of the heterogeneity in disease presentation and limited clinical expertise outside of a few specialized centers. Additionally, many rare diseases have poorly characterized natural histories. Phenotypic diversity within a disorder adds to the complexity in describing its natural history. Furthermore, because the number of patients for each rare disease is small, the study design is often restricted in clinical development programs. Clinical endpoints, such as potential biomarkers, are often not well-defined and may not have regulatory precedence.

Since most rare conditions have no FDA approved treatments, physicians treating patients with rare diseases strongly rely on off-label drug use. Unfortunately, rare diseases are not often investigated within peer-reviewed journal articles and the results from failed clinical trials are rarely published. Due to a lack of communication of benefits for off-label use and limited diffusion of offlabel information, many physicians who treat individuals with rare diseases are unaware of potential benefits of off-label use of therapies for their patients. Even if they are aware, information that is available generally is not specific to a particular rare disease, leaving substantial uncertainty on how to care for these patients using the off-label drug. Table 1 summarizes current needs and challenges of using off-label medications in rare pediatric diseases.

Another important barrier for individuals with rare diseases is obtaining insurance coverage for off-label therapies. In general, insurers and pharmacy benefit managers (PBM) will not reimburse off-label use of drugs or medical devices. Due to the rejection of coverage of off-label therapies for rare diseases, patients are required to mostly pay out of pocket or provide additional paperwork which delays patient access. These patients are forced to pay thousands of dollars just to

Table 1. Current needs and challenges of using off-label medication in rare pediatric diseases

\begin{tabular}{|c|c|}
\hline Needs and Challenges & Rationale \\
\hline $\begin{array}{l}\text { Current needs of using } \\
\text { off-label medication }\end{array}$ & $\begin{array}{l}\text { Lack of studies in children often leads to off-label usage of drugs in children. There are delays in conducting clinical trials } \\
\text { with children due to } \\
\text { - Lack of financial incentives for sponsors to conduct drug trials with children } \\
\text { - Many diseases are less common in children than in adults, so it requires more time to recruit child participants } \\
\text { - Concerns regarding ethics, harm, and consent, making it difficult to obtain institutional review board approval to } \\
\text { conduct clinical trials with children }\end{array}$ \\
\hline & $\begin{array}{l}\text { Unique challenges in conducting clinical trials in rare pediatric diseases: } \\
\text { - Frequently underdiagnosed because of the heterogeneity in dis-ease presentation and limited clinical expertise } \\
\text { outside of a few specialized centers } \\
\text { - Natural histories are poorly characterized and phenotypic diversity within a disorder adds to the complexity } \\
\text { - Study design is often restricted due to a small number of patients for each disorder } \\
\text { - Clinical endpoints, e.g. biomarkers, are often not well-defined and there may be no regulatory precedence }\end{array}$ \\
\hline $\begin{array}{l}\text { Challenges of using } \\
\text { off-label medication }\end{array}$ & $\begin{array}{l}\text { There is substantial uncertainty for physicians to care for their patients with rare diseases using the off-label drug due to } \\
\text { - Rare diseases are not often investigated within peer-reviewed journal articles } \\
\text { - Results from failed clinical trials are rarely published } \\
\text { - Lack of communication of benefits for off-label use and limited diffusion of off-label information } \\
\text { - Even the information that is available generally is not specific to a particular rare disease }\end{array}$ \\
\hline
\end{tabular}


access therapies prescribed off-label $(10,11)$. This results in an equality issue where only the wealthy can afford off-label treatment, while patients with lower incomes cannot.

\section{Medication uses in recent pediatric clinical practice}

Pediatric patients with rare diseases represent a population which has a high likelihood for off-label drug use. As an example, several biologics are approved for the indication of juvenile idiopathic arthritis (JIA). However, many children with JIA continue to have active disease despite treatment and are treated with other offlabel biologics, including anakinra, ustekinumab and golimumab (12). Infliximab and golimumab, which are not approved for JIA, are considered potential treatment options, particularly in JIA patients with rheumatoid factor positive where previous therapy was ineffective or not tolerated (13). Table 2 shows the off-label biologic agents for treatment of JIA. A retrospective study showed $\sim 5 \%$ of JIA patients were prescribed off-label biologic agents as their first-course treatment and more than $20 \%$ of patients were prescribed off-label biologics as their second-course therapy (14). The proportion of children with an off-label biologic disease-modifying antirheumatic drug (DMARDs) prescription after JIA diagnosis increased over time (Figure 1). Near $15 \%$ of patients were treated with off-label biologic DMARDs on average over the ten-year period from 2009 to 2018, and off-label use of biologics was increasing from $0.0 \%$ in 2009 to $17.2 \%$ in 2018, peaking at $28.3 \%$ in 2015 .

An important reason for use of off-label drugs is to improve access to new treatments or to address the medical needs and preferences of patients. In general, off-label use of medicines is not supported by the same level of evidence as drugs FDA approved for pediatric use. This may result in increased uncertainty on efficacy as well as the risk for toxicity and other adverse events. Recently, more studies have been conducted to describe off-label use of new treatments, such as biologics in children with rare diseases (15-17).

\section{Regulations for rare pediatric diseases}

Since the number of patients is small for each rare disease, there is a lack of financial incentives for sponsors to conduct drug trials for these conditions. Legislation has promoted orphan drug development.

Table 2. Biologic agents for treatment of juvenile idiopathic arthritis

\begin{tabular}{|c|c|c|c|c|}
\hline Mechanism of action & Generic Name & Route & FDA Approval Date for JIA & FDA First Approval Date \\
\hline TNF inhibitor & $\begin{array}{l}\text { Adalimumab } \\
\text { Certolizumab Pegol } \\
\text { Etanercept } \\
\text { Infliximab } \\
\text { Golimumab }^{*}\end{array}$ & $\begin{array}{l}\text { Injection } \\
\text { Injection } \\
\text { Injection } \\
\text { Infusion } \\
\text { Injection/Infusion }\end{array}$ & $\begin{array}{l}2 / 22 / 2008 \\
\text { NA } \\
5 / 27 / 1999 \\
\text { NA } \\
\text { NA }\end{array}$ & $\begin{array}{r}12 / 31 / 2002 \\
4 / 22 / 2008 \\
11 / 2 / 1998 \\
8 / 24 / 1998 \\
4 / 24 / 2009\end{array}$ \\
\hline $\begin{array}{l}\text { Binds to CD } 80 / C D 86 \text { and inhibits } \\
\text { T-cell costimula-tory signal }\end{array}$ & Abatacept & Injection/Infusion & $10 / 28 / 2008$ & $12 / 23 / 2005$ \\
\hline IL-1 inhibitor & $\begin{array}{l}\text { Canakinumab } \\
\text { Rilonacept } \\
\text { Anakinra }^{*}\end{array}$ & $\begin{array}{l}\text { Injection } \\
\text { Injection } \\
\text { Injection }\end{array}$ & $\begin{array}{l}5 / 10 / 2013 \\
\text { NA } \\
\text { NA }\end{array}$ & $\begin{array}{r}6 / 17 / 2009 \\
2 / 27 / 2008 \\
11 / 14 / 2001\end{array}$ \\
\hline $\begin{array}{l}\text { IL-6 inhibitor } \\
\text { Binds CD20 on B-cell } \\
\text { IL-12/IL-23 inhibitor }\end{array}$ & $\begin{array}{l}\text { Tocilizumab } \\
\text { Rituximab }^{*} \\
\text { Ustekinumab }^{*}\end{array}$ & $\begin{array}{l}\text { Injection/Infusion } \\
\text { Infusion } \\
\text { Injection }\end{array}$ & $\begin{array}{l}\text { 4/30/2013 } \\
\text { NA } \\
\text { NA }\end{array}$ & $\begin{array}{r}1 / 8 / 2010 \\
11 / 26 / 1997 \\
9 / 25 / 2009\end{array}$ \\
\hline
\end{tabular}

CD, cluster of differentiation; TNF, tumor necrosis factor; IL, interleukin; JIA, juvenile idiopathic arthritis. "Off-label uses of biologic agents to treat juvenile idiopathic arthritis.

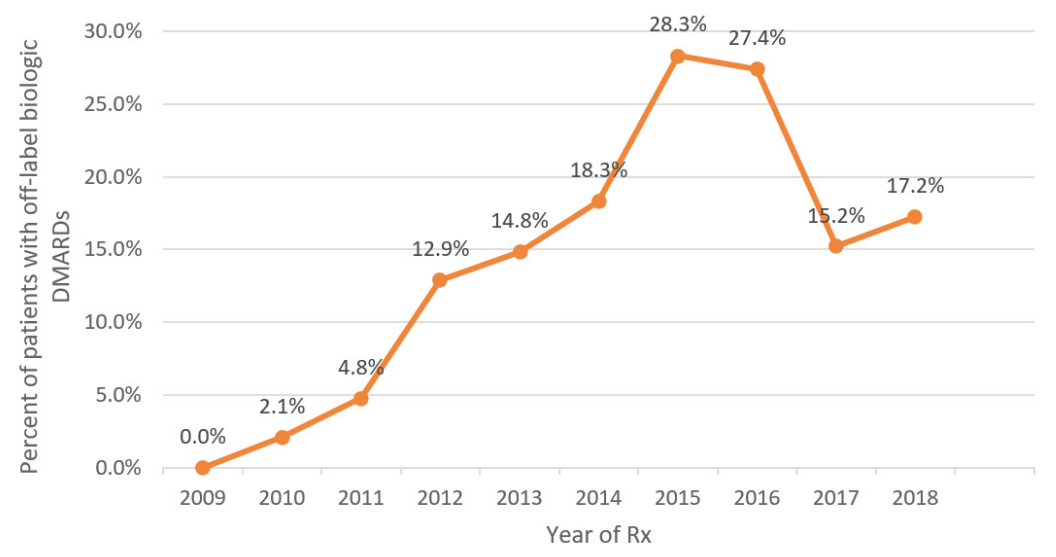

www.irdrjournal.com
Figure 1. Annual proportions of patients receiving off-label biologic disease-modifying antirheumatic drug (DMARDs) after juvenile idiopathic arthritis diagnosis by calendar year, 2009-2018 $(33,34)$. 
The Orphan Drug Act of 1983 made substantial progress in promoting development of products for diagnosis and treatment of rare diseases (5). The policy created economic incentives to promote development of new treatments for rare diseases, including: i) 7 years of market exclusivity for approved orphan products; $i$ ) $25 \%$ tax credit for clinical study costs and user fee waivers; iii) eligibility to apply for FDA Orphan Grants program to support clinical research.

To motivate sponsors to conduct drug trials for lifethreatening rare pediatric diseases, the Creating Hope Act was established in 2012. As part of the act, the rare pediatric disease priority review voucher program (PRV) was created (18). The act changed the way that pharmaceutical companies look at rare pediatric diseases dramatically. In the prior 20 years, there were very few drugs developed for treating the pediatric population that were FDA approved for children. But after the PRV was approved, many pharmaceutical companies started to develop drugs for children with cancer and other lifethreatening illnesses because of the incentives. These incentives include: $i$ ) vouchers awarded when a new drug is approved for a rare pediatric disease (e.g., Duchenne muscular dystrophy); $i$ ) future product gets a 6-month priority review timeline (instead of usual 10-month standard review). Since 2012, 28 rare pediatric disease vouchers have been awarded by the FDA (19).

A large portion of rare diseases are rare cancers. Altogether, there are about 6,000 types of cancer identified (20). Nineteen of these cancers are common diseases (e.g., lung, colorectal, breast, pancreas, prostate) and the remaining cancers are rare diseases under US
Public Law $(21,22)$. Rare cancers account for about 20\% of all cancers diagnosed (21) and all forms of pediatric cancer are rare by definition. DeSantis et al. reported that more than two-thirds $(71 \%)$ of cancers occurring in children and adolescents are rare cancers compared with less than $20 \%$ of cancers diagnosed in patients aged 65 years and older. The 5-year relative survival for rare cancers is poorer than that for common cancers among both males (55\% vs. $75 \%$ ) and females (60\% vs. 74\%). While survival rates have improved for certain pediatric cancers, malignant neoplasms were the third leading cause of death, representing $9 \%$ of overall deaths among children and adolescents (23).

In August 2017, the Research to Accelerate Cures and Equity (RACE) for Children Act was signed into law as part of the 2017 FDA Reauthorization Act (24). The purpose of the RACE for Children Act was to promote development of new cancer treatments for children. The RACE Act gives the FDA authority to require any new cancer drug to be studied in pediatric cancers if the molecular target of the cancer drug is relevant. Cancer drugs with orphan designations are no longer exempt from PREA requirements. RACE for Children Act amended PREA to require pediatric investigation of certain targeted cancer drugs based on molecular mechanisms of action rather than the clinical indication for original Novel Drug Applications (NDAs) and Biologics License Applications (BLAs) submitted on or after August 18,2020, unless a deferral or waiver is granted. Table 3 highlights important regulations and core content for rare pediatric diseases including rare cancers in the last 10 years (2011-2021).

Table 3. Important regulations and core content for rare pediatric diseases including rare cancers in the last 10 years (2011-2021)

\begin{tabular}{|c|c|c|}
\hline Public Law & Subsequent Law & Program/Regulation for Rare Pediatric Disease \\
\hline $\begin{array}{l}\text { 21 }^{\text {st }} \text { Century Cures Act } \\
\text { - Enacted on December 13, } 2016 \\
\text { - To help accelerate medical product } \\
\text { development and bring new innovations } \\
\text { and advances to patients who need them } \\
\text { faster and more efficiently } \\
\text { - Major driver of } 21^{\text {st }} \text { Century Cures } \\
\text { Act was patients with rare diseases } \\
\text { - Renewed the Creating Hope Act of } \\
2012 \\
\text { - The rare pediatric disease priority re- } \\
\text { view voucher pro-gram (PRV) was created }\end{array}$ & $\begin{array}{l}\text { Advancing Hope Act of } \mathbf{2 0 1 6} \\
\text { - Strengthens and extends the PRV } \\
\text { through September } 30,2020\end{array}$ & $\begin{array}{l}\text { Rare Pediatric Disease Priority Review Vouchers Program } \\
\text { - Intended to create a market incentive for the development } \\
\text { of drugs for rare pediatric diseases through the establishment } \\
\text { of a priority review voucher } \\
\text { - Voucher awarded when a new drug approved for a rare } \\
\text { pediatric disease (e.g., Duchenne muscular dystrophy) } \\
\text { - Future product gets a 6-month priority review time clock } \\
\text { (instead of usual 10-month standard review) } \\
\text { - Vouchers can be sold }\end{array}$ \\
\hline $\begin{array}{l}\frac{\text { Food and Drug Administration }}{\text { Reauthorization Act (FDARA) }} \\
\text { - Signed into law on August } 18,2017 \\
\text { - Revises and extends the user-fee } \\
\text { programs for drugs, medical devices, } \\
\text { generic drugs, and biosimilar biological } \\
\text { products } \\
\text { - Updates the } 2003 \text { Pediatric Research } \\
\text { Equity Act (PREA) }\end{array}$ & $\begin{array}{l}\text { - } \text { Research to Accelerate Cures } \\
\text { \& Equity Act (RACE) } \\
\text { ○ Enacted on August 18, } 2017 \\
\text { ○ Incorporated as Title V of the } \\
\text { FDARA } \\
\text { O Aim to promote research into, } \\
\text { and development of, new treatments } \\
\text { for children with cancer }\end{array}$ & $\begin{array}{l}\text { Research to Accelerate Cures \& Equity Act (RACE) } \\
\text { - Provides the FDA the authority to require any new } \\
\text { cancer drug to be studied in pediatric cancers for which the } \\
\text { molecular target of the cancer drug is relevant } \\
\text { - Amended PREA to require pediatric investigation of } \\
\text { certain targeted cancer drugs based on molecular mechanisms } \\
\text { of action rather than the clinical indication for original BLAs/ } \\
\text { NDAs submitted on or after August } 18,2020 \text {, unless a deferral } \\
\text { or waiver is granted } \\
\text { - Cancer drugs with orphan designations no longer exempt } \\
\text { from PREA requirements }\end{array}$ \\
\hline
\end{tabular}


Table 4. Number of novel drug approvals (NDA) by the Center for Drug Evaluation and Research (CDER) from 2017 to August 2021

\begin{tabular}{lcccc}
\hline Number (\%) & 2017 & 2018 & 2019 & 2020 \\
\hline All NDAs approved & 46 & 59 & 48 & 53 \\
NDAs for rare diseases (adults and children) & $18(39 \%)$ & $34(58 \%)$ & $21(44 \%)$ & $31(58 \%)$ \\
NDAs for rare pediatric diseases & $6(33 \%)$ & $9(26 \%)$ & $7(33 \%)$ & $15(48 \%)$ \\
\hline
\end{tabular}

\section{Recent drug approvals for rare pediatric diseases}

Thanks to the regulations set up specifically for rare pediatric diseases, recent orphan drug development has increased the availability of treatments. The study by Kimmel et al. showed that among 402 orphan indications approved by the FDA between 2010 and 2018 (25), 136 (33.8\%) were for pediatric orphan indications. There is an increasing trend in the number of FDA-approved pediatric orphan indications. For instance, there were eight pediatric orphan indications in 2010, 18 in 2014, 12 in 2015, 27 in 2017, and 29 in 2018. Most of the pediatric orphan indications used existing drugs and many targeted the same disease. However, there is still a substantial unmet need for treatments in most pediatric rare diseases.

On the FDA website, we evaluated novel drug approvals by the Center for Drug Evaluation and Research (CDER) for rare pediatric diseases from 2017 to August 2021 (Table 4). For instance, in 2019, 21 of the 48 novel drugs approved by CDER (44\%) were for treatments of rare diseases (26). Among these 21 orphan indications, seven $(33 \%)$ were for rare pediatric diseases. In 2020, 31 of CDER's 53 novel drug approvals $(58 \%)$ were approved to treat rare diseases (27). The percentage of orphan indications for rare pediatric diseases was much higher in 2020 (15 out of 31, 48\%). Notable examples of novel approvals of 2020 to treat pediatric rare diseases include Evrysdi (risdiplam) to treat patients two months of age and older with spinal muscular atrophy (SMA), a rare and often fatal genetic disease affecting muscle strength and movement (28) and Lampit (nifurtimox), to treat Chagas disease (a rare parasitic disease which, if left untreated, can cause congestive heart failure) in children less than 18 years of age (29). For 2021, as of August, the percentage of orphan indications for rare pediatric diseases remained high (47\%).

Table 5 lists drug name and indication for recent novel drug approvals for rare pediatric diseases from 2017 to August 2021. Duchenne muscular dystrophy is the most studied rare condition with NDA each year from 2017 to 2021, except for 2018. The number of NDA for rare cancers remains small, ranging from 1 to 3 each year from 2017 to 2021.

\section{Discussion}

Off-label treatment remains an important public health issue for neonates, infants, children, and adolescents, especially for pediatric patients with rare diseases. Many pediatric patients with rare diseases use drugs off-label due to limited data for pediatric patients. Lack of studies in children often leads to off-label usage of drugs. There are delays in conducting clinical trials with children due to lack of financial incentives for sponsors to conduct drug trials with children, and difficulties to obtain institutional review board approval owing to ethical and clinical concerns.

There are over 7,000 known rare diseases and $~ 50 \%$ of people affected by rare diseases are children. While significant advances in the development and approval of rare disease therapies have been made, most rare conditions still have no FDA approved treatments. Unique challenges in conducting clinical trials in rare pediatric diseases, e.g. poorly characterized natural history of the disease, and a small number of patients for each disorder contribute to the delays in conducting clinical trials with children.

We support FDA efforts in promoting orphan drug development for rare pediatric diseases. For instance, recent developments in legislation, in particular, the rare pediatric disease priority review voucher program has been successful. As shown in the Kimmel study, it is encouraging that there is an increasing trend in the number of FDA-approved pediatric orphan indications over time. We found that the percentage of orphan indications for rare pediatric diseases increased to near $50 \%$ in 2020 and 2021 among the novel drug approvals by CDER from 2017 to August 2021. In addition, the RACE for Children Act was set up to promote the development of new treatments for rare cancers in children, which are a large portion of rare diseases. Although the number of new drug approvals for rare cancers remains small from 2017 to 2021, it may be too early to see the impact from the RACE for Children Act. There should be a significant increase in new drug approvals for rare cancers in children in the near future.

In addition, several efforts from FDA to address unique challenges in conducting clinical trials in rare diseases, including regulatory innovations and flexibilities significantly contributed to several orphan drug approvals. These include adaptive trial design, external control arm based on real-world data, etc. The FDA describes the adaptive trial design as "a clinical trial design that allows for prospectively planned modifications to one or more aspects of the design based on accumulating data from subjects in the trial" 
Table 5. Recent novel drug approvals for rare pediatric diseases, 2017-August 2021

\begin{tabular}{|c|c|c|c|c|c|}
\hline Year & 2017 & 2018 & 2019 & 2020 & 2021 \\
\hline 1 & $\begin{array}{l}\text { Hemlibra for hemophilia } \\
\text { A who have developed } \\
\text { antibodies called Factor } \\
\text { VIII (FVIII) inhibitors }\end{array}$ & $\begin{array}{l}\text { Crysvita for x-linked } \\
\text { hypophosphatemia (XLH) }\end{array}$ & $\begin{array}{l}\text { Adakveo for } \\
\text { vasoocclusive crisis }\end{array}$ & Artesunate for severe malaria & $\begin{array}{l}\text { Evkeeza for } \\
\text { homozygous familial } \\
\text { hypercholesterolemia }\end{array}$ \\
\hline 2 & $\begin{array}{l}\text { Mepsevii for } \\
\text { mucopolysaccharidosis } \\
\text { type VII (MPS VII) }\end{array}$ & $\begin{array}{l}\text { Epidiolex for Lennox- } \\
\text { Gastaut syndrome and Dravet } \\
\text { syndrome }\end{array}$ & Egaten for fascioliasis & $\begin{array}{l}\text { Danyelza for refractory or } \\
\text { relapsed neuroblastoma }\end{array}$ & $\begin{array}{l}\text { Amondys } 45 \text { for Duchenne } \\
\text { muscular dystrophy }\end{array}$ \\
\hline 3 & $\begin{array}{l}\text { Benznidazole for Chagas } \\
\text { disease }\end{array}$ & $\begin{array}{l}\text { Elzonris for blastic } \\
\text { plasmacytoid dendritic cell } \\
\text { neoplasm (BPDCN) }\end{array}$ & $\begin{array}{l}\text { Oxbrytax for sickle } \\
\text { cell disease }\end{array}$ & $\begin{array}{l}\text { Dojolvi for fatty acid } \\
\text { oxidation disorders }\end{array}$ & $\begin{array}{l}\text { Rylaze for acute } \\
\text { lymphoblastic leukemia } \\
\text { and lymphoblastic } \\
\text { lymphoma }\end{array}$ \\
\hline 4 & $\begin{array}{l}\text { Brineura for a specific } \\
\text { form of Batten disease }\end{array}$ & $\begin{array}{l}\text { Asparlas for acute } \\
\text { lymphoblastic leukemia } \\
\text { (ALL) }\end{array}$ & $\begin{array}{l}\text { Rozlytrek for } \\
\text { metastatic solid tumors }\end{array}$ & $\begin{array}{l}\text { Ebanga for Zaire Ebola virus } \\
\text { infection }\end{array}$ & $\begin{array}{l}\text { Fexinidazole for human } \\
\text { African trypanosomiasis }\end{array}$ \\
\hline 5 & $\begin{array}{l}\text { Bavencio for metastatic } \\
\text { Merkel cell carcinoma }\end{array}$ & $\begin{array}{l}\text { Vitrakvi solid tumors } \\
\text { with a biomarker called } \\
\text { a neurotrophic receptor } \\
\text { tyrosine kinase (NTRK) gene } \\
\text { fusion }\end{array}$ & $\begin{array}{l}\text { Trikafta for cystic } \\
\text { fibrosis }\end{array}$ & $\begin{array}{l}\text { Evrysdi for spinal muscular } \\
\text { atrophy }\end{array}$ & $\begin{array}{l}\text { Rezurock for chronic graft- } \\
\text { versus-host disease after } \\
\text { failure of at least two prior } \\
\text { lines of systemic therapy }\end{array}$ \\
\hline 6 & $\begin{array}{l}\text { Emflaza for Duchenne } \\
\text { muscular dystrophy }\end{array}$ & $\begin{array}{l}\text { Takhzyro for types I and II } \\
\text { hereditary angioedema }\end{array}$ & $\begin{array}{l}\text { Vyondys } 53 \text { for } \\
\text { Duchenne muscular } \\
\text { dystrophy }\end{array}$ & $\begin{array}{l}\text { Imcivree for obesity } \\
\text { associated with pro- } \\
\text { opiomelanocortin deficiency }\end{array}$ & Bylvay for pruritus \\
\hline 7 & & $\begin{array}{l}\text { Diacomit for Dravet } \\
\text { syndrome }\end{array}$ & $\begin{array}{l}\text { Ga-68-DOTATOC } \\
\text { for somatostatin } \\
\text { receptor positive } \\
\text { neuroendocrine tumors } \\
\text { (NETs) }\end{array}$ & $\begin{array}{l}\text { Inmazeb for Zaire Ebola } \\
\text { virus infection }\end{array}$ & $\begin{array}{l}\text { Nexviazyme for late-onset } \\
\text { Pompe disease }\end{array}$ \\
\hline 8 & & $\begin{array}{l}\text { Moxidectin for } \\
\text { onchocerciasis due to } \\
\text { Onchocerca volvulus }\end{array}$ & & $\begin{array}{l}\text { Koselugo for } \\
\text { neurofibromatosis type } 1\end{array}$ & $\begin{array}{l}\text { Skytrofa for short stature } \\
\text { due to inadequate secretion } \\
\text { of endogenous growth } \\
\text { hormone }\end{array}$ \\
\hline 9 & & $\begin{array}{l}\text { Symdeko for cystic fibrosis } \\
\text { with a certain type of genetic } \\
\text { mutation }\end{array}$ & & Lampit for Chagas disease & \\
\hline 10 & & & & $\begin{array}{l}\text { Orladeyo for hereditary } \\
\text { angioedema }\end{array}$ & \\
\hline 11 & & & & $\begin{array}{l}\text { Oxlumo for hyperoxaluria } \\
\text { type } 1\end{array}$ & \\
\hline 12 & & & & $\begin{array}{l}\text { Retevmo for metastatic } \\
\text { medullary thyroid cancer }\end{array}$ & \\
\hline 13 & & & & $\begin{array}{l}\text { Viltepso for Duchenne } \\
\text { muscular dystrophy }\end{array}$ & \\
\hline 14 & & & & $\begin{array}{l}\text { Zokinvy for Hutchinson- } \\
\text { Gilford Progeria Syndrome }\end{array}$ & \\
\hline 15 & & & & $\begin{array}{l}\text { Tazverik for epithelioid } \\
\text { sarcoma }\end{array}$ & \\
\hline
\end{tabular}

(30). One potential advantage of adaptive trial design is statistical efficiency. An adaptive design may provide the same statistical power with smaller expected sample size or shorter expected duration, which works well for rare diseases since the number of patients for each rare disease is small.

The FDA website's page titled "Rare Diseases: Natural History Studies for Drug Development Guidance for Industry" states that natural history study data may be used as an external control for clinical investigations (31).
Natural history study data were used to support several orphan drug approvals. For instance, in 2015, the FDA approved asfotase alfa (Strensiq ${ }^{\mathrm{TM}}$ ), for the treatment of patients with perinatal/infantile- and juvenile-onset hypophosphatasia (HPP) (32). The approval of asfotase alfa was based on two multicenter, single-arm, phase 2 interventional studies in 68 treated patients, compared with 48 patients with similar age and HPP characteristics from a retrospective natural history study. In addition, the FDA has set up the Orphan Products Natural History 
Grant Program (19), which has supported a number of natural history studies to address several challenges during the clinical development programs of drugs and biological products for rare diseases.

Although substantial efforts and significant advances in the development and approval of rare disease therapies have been made, there is still a substantial unmet need for new treatments in most pediatric rare diseases. Currently less than $10 \%$ of rare diseases have an FDAapproved drug. Even though some rare conditions have FDA approved drugs, some patients continue to use off-label medications due to active disease, disease progression, patient preference or others. For instance, in the article by $\mathrm{Yu}$ et al. to evaluate biologics for children with JIA, many children continue to be treated with offlabel biologics.

There is substantial uncertainty for physicians to care for their patients with rare diseases using off-label drugs. To address this issue, there are several areas potentially for the scientific community to assist. For instance, peerreviewed journal articles could promote and encourage submission and publication of articles investigating offlabel medication use in rare pediatric diseases in a format such as a case report, review article or others. In addition, it would be helpful for clinical and scientific societies to promote and encourage information sharing on off-label medication use, and to create a forum to allow discussion of potential benefits or challenges for rare pediatric diseases through webinars, workshops or others.

In conclusion, the present study demonstrates the ongoing medical need for newly approved medications to treat pediatric rare diseases and revealed the positive impact of regulations from the Orphan Drug Act of 1983 to the RACE for Children Act on drug development and off-label medication practice in rare pediatric disease management. This article provides informative historical background and current considerations of the off-label use of medication in neonates, infants, children, and adolescents with rare diseases.

\section{Funding: None.}

Conflict of Interest: Dr. Guo has received research grant or unrestricted grant funding from the following: the Ohio Department of Jobs and Family Services (Medicaid Agency), Ortho-McNeil Janssen Scientific Affairs LLC, Eli-Lilly Company, Novartis Company and RocheGenentech Company. The authors declare that there is no conflict of interest concerning this research. The opinions and conclusions expressed in this manuscript are solely those of the authors.

\section{References}

1. U.S. Congress. Pediatric research equity act of 2003. Public Law, 108155. https://www.congress.gov/108/plaws/ publ155/PLAW-108publ155.pdf (accessed September 18, 2021).
2. U.S. Congress. Best Pharmaceuticals For Children Act. Public Law, 107109. https://www.congress.gov/107/plaws/ publ109/PLAW-107publ109.pdf (accessed September 18, 2021).

3. Hoon D, Taylor MT, Kapadia P, Gerhard T, Strom BL, Horton DB. Trends in off-label drug use in ambulatory settings: 2006-2015. Pediatrics. 2019; 144:e20190896.

4. Genetic and Rare Diseases (GARD) Information Center. FAQs about rare diseases. https://rarediseases.info.nih. gov/diseases/pages/31/fags-about-rare-diseases (accessed June 20, 2021).

5. U.S. Congress. Orphan Drug Act. Public Law, 97144. https://www.fda.gov/media/99546/download (accessed September 18, 2021).

6. U.S. Food and Drug Administration. Rare Disease Day 2018. https://www.fda.gov/industry/orphan-productsdevelopment-events/rare-disease-day-2018 (accessed June 20, 2021).

7. U.S. Food and Drug Administration. Rare Disease Day 2021. https://www.fda.gov/news-events/fda-voices/raredisease-day-2021-fda-shows-sustained-support-raredisease-product-development-during-public (accessed June 20, 2021).

8. Markham A. Cerliponase alfa: first global approval. Drugs. 2017; 77:1247-1249.

9. Kohlschuetter A, Schulz A. CLN2 disease (classic late infantile neuronal ceroid lipofuscinosis). Pediatr Endocrinol Rev. 2016; 13 Suppl:682-688.

10. Burns TM, Crowell JL, Smith AG. A crisis in US drug pricing: Consequences for patients with neuromuscular diseases, physicians and society, part 1 . Muscle Nerve. 2020; 62:567-572.

11. IQVIA Institute for Human Data Science. Orphan drugs in the United States: growth trends in rare disease treatments. 2018. https://www.iqvia.com/-/media/iqvia/pdfs/institutereports/orphan-drugs-in-the-united-states-growth-trendsin-rare-disease-treatments.pdf?_=1575565762648 (accessed July 11, 2021).

12. Brunner HI, Schanberg LE, Kimura Y, et al. New medications are needed for children with juvenile idiopathic arthritis. Arthritis Rheumatology. 2020; 72:1945-1951.

13. NHS England. Clinical commissioning policy statement: biologic therapies for the treatment of juvenile idiopathic arthritis (JIA). https://www.england.nhs.uk/commissioning/ wp-content/uploads/sites/12/2015/10/e03pd-biotherapies-jia-oct15.pdf (accessed June 14, 2021).

14. Yue X, Huang B, Hincapie AL, Wigle PR, Qiu T, Li Y, Morgan EM, Guo J. Prescribing patterns and impact of factors associated with time to initial biologic therapy among children with non-systemic juvenile idiopathic arthritis. Pediatric Drugs. 2021; 23:171-182.

15. AlAzmi A, Alasmari Z, Yousef C, Alenazi A, AlOtaibi M, AlSaedi H, AlShaikh A, AlObathani A, Ahmed O, Goronfolah L, Alahmari M. Off-label drug use in pediatric out-patient care: a multi-center observational study. Hospital Pharmacy.

16. Pin A, Tesser A, Pastore S, Moressa V, Valencic E, Arbo A, Maestro A, Tommasini A, Taddio A. Biological and clinical changes in a pediatric series treated with off-label jak inhibitors. Int J Mol Sci. 2020; 21:7767.

17. Schrier L, Hadjipanayis A, Stiris T, Ross-Russell R, Valiulis A, Turner M, Zhao W, Cock P, Wildt S, Allegaert K, Anker J. Off-label use of medicines in neonates, infants, children, and adolescents: a joint policy statement by the 
European academy of paediatrics and the European society for developmental perinatal and pediatric pharmacology. Eur J Pediatr. 2020; 179:839-847.

18. U.S. Food and Drug Administration. Rare pediatric disease priority review vouchers https://www.fda.gov/ regulatory-information/search-fda-guidance-documents/ rare-pediatric-disease-priority-review-vouchers (accessed June 20, 2021).

19. U.S. Food and Drug Administration. FDA drug topics: FDA's office of orphan products development (OOPD) - an overview and update - April 26, 2021. https://www. fda.gov/about-fda/fda-pharmacy-student-experientialprogram/fda-drug-topics-fdas-office-orphan-productsdevelopment-oopd-overview-and-update-april-26-2021 (accessed June 20, 2021).

20. Berman JJ. Tumor taxonomy for the developmental lineage classification of neoplasms. BMC cancer. 2004; 4:88

21. DeSantis CE, Kramer JL, Jemal A. The burden of rare cancers in the United States. CA Cancer J Clin. 2017; 67:261-272.

22. U.S. Congress. Rare Diseases Act of 2002, Public Law 107-280, 107th US Congress, (2002). https://www. congress.gov/107/plaws/publ280/PLAW-107publ280.pdf (accessed September 18, 2021).

23. Cunningham RM, Walton MA, Carter PM. The major causes of death in children and adolescents in the United States. N Engl J Med. 2018; 379:2468-2475.

24. U.S. Congress. FDA Reauthorization Act of 2017. Public Law, 11552. https://www.congress.gov/115/plaws/publ52/ PLAW-115publ52.pdf (accessed September 18, 2021).

25. Kimmel L, Conti RM, Volerman A, Chua K-P. Pediatric orphan drug indications: 2010-2018. Pediatrics. 2020; 145:e20193128.

26. U.S. Food and Drug Administration. Novel drug approvals for 2019. https://www.fda.gov/drugs/new-drugs-fda-cdersnew-molecular-entities-and-new-therapeutic-biologicalproducts/novel-drug-approvals-2019 (accessed June 27, 2021).

27. U.S. Food and Drug Administration. Novel drug approvals for 2020. https://www.fda.gov/drugs/new-drugs-fda-cdersnew-molecular-entities-and-new-therapeutic-biologicalproducts/novel-drug-approvals-2020 (accessed June 27, 2021).

28. U.S. Food and Drug Administration. Drug trials snapshots:
EVRYSDI. https://www.fda.gov/drugs/drug-approvalsand-databases/drug-trials-snapshots-evrysdi (accessed June 27, 2021).

29. U.S. Food and Drug Administration. Drug trials snapshots: LAMPIT. https://www.fda.gov/drugs/developmentapproval-process-drugs/drug-trials-snapshots-lampit (accessed June 27, 2021).

30. U.S. Department of Health and Human Services. Adaptive designs for clinical trials of drugs and biologics - guidance for industry https://www.fda.gov/media/78495/download (accessed June 27, 2021).

31. U.S. Department of Health and Human Services. Draft guidance: Rare diseases: Natural history studies for drug development. Food \& Drug administration. https://www. fda.gov/media/122425/download (accessed June 27, 2021).

32. Whyte MP, Rockman-Greenberg C, Ozono K, Riese R, Moseley S, Melian A, Thompson D, Bishop N, Hofmann C. Asfotase alfa treatment improves survival for perinatal and infantile hypophosphatasia. J Clin Endocrinol Metab. 2016; 101:334-342.

33. Huang B, Qiu T, Chen C, Neace A, Zhang Y, Yue X, Zahner J, Adams M, Seid M, Lovell D, Morgan E, Brunner H. Comparative effectiveness research using electronic health records data: ensure data quality. SAGE research methods cases. 2020.

34. Yue X, Huang B, Hincapie AL, Wigle PR, Li Y, Qiu T, Lovell D Morgan EM, Guo JJ. Comparative effectiveness and persistence of TNFi and non-TNFi in juvenile idiopathic arthritis: a large paediatric rheumatology centre in the USA. Rheumatology (Oxford). 2021; 60:40634073 .

Received July 19, 2021; Revised September 26, 2021 ; Accepted October 4, 2021.

*Address correspondence to:

Xiaomeng Yue, Division of Pharmacy Practice \& Administrative Sciences, James L. Winkle College of Pharmacy, University of Cincinnati, Cincinnati, 3225 Eden Ave., Cincinnati, OH 45267, USA.

E-mail: yuexn@mail.uc.edu

Released online in J-STAGE as advance publication October $15,2021$. 